\title{
A Refinement of the Crystal Structure of Tellurium Dibenzenethiosulphonate
}

\author{
KJELL ASE \\ Chemical Institute, University of Bergen, N.5000 Bergen, Norway
}

\begin{abstract}
The crystal structure of tellurium dibenzenethiosulphonate, $\mathrm{Te}\left(\mathrm{S}_{2} \mathrm{O}_{2} \mathrm{C}_{6} \mathrm{H}_{5}\right)_{2}$, has been refined by full-matrix least squares methods, using three-dimensional diffractometer data, to a conventional $R$ value of 0.038 . The crystals are orthorhombic, space group Pbcn (No. 60), with $a=14.467 \AA, b=11.137 \AA, c=10.455 \AA$, and four molecules in the unit cell.

The tellurium atom of the nonplanar $S-S-T e-S-S$ chain lies on a two-fold axis, and the molecule thus occurs in a trans form. The following dimensions of the chain, with standard deviations in parentheses, have been found: $\mathrm{Te}-\mathrm{S}=\mathbf{2 . 3 8 0 ( 2 )} \AA, \mathrm{S}-\mathrm{S}=2.080(2) \AA$, $\angle \mathrm{S}-\mathrm{Te}-\mathrm{S}=97.61(6)^{\circ}, \angle \mathrm{S}-\mathrm{S}-\mathrm{Te}=103.46(7)^{\circ}$. The dihedral angle between the $\mathrm{S}-\mathrm{S}-\mathrm{Te}$ and $\mathrm{S}-\mathrm{Te}-\mathrm{S}$ planes is $97.4^{\circ}$.
\end{abstract}

$\mathrm{T}$ he crystal structure of a trans square-planar complex of tellurium dibenzenethiosulphonate with trimethylenethiourea ${ }^{1}$ was recently reported, and the structures of two similar complexes, one with ethylenethiourea and another with tetramethylthiourea, are under study in this Laboratory. In connection with investigations of this type of complex, it was thought of interest to refine the structure of uncomplexed tellurium dibenzenethiosulphonate, which was reported in 1956 by Øyum and Foss. ${ }^{2}$ With more modern facilities, it should be possible to determine the structural parameters more accurately. The lengths of the Te-S and S-S bonds are of special interest for comparison with the correspondirg bond lergths in the complexes mentioned above.

\section{EXPERIMENTAL}

The yellow orthorhombic crystals of $\mathrm{Te}\left(\mathrm{S}_{2} \mathrm{O}_{2} \mathrm{C}_{6} \mathrm{H}_{5}\right)_{2}$ were prepared by Foss. ${ }^{3}$

The data collertion was made by means of a Siemens automatic, off-line, single crystal diffractometer (AED), using (Ni-filtered) $\mathrm{Cu} K \alpha$ radiation. The diffractometer was operated as a three-circle instrument.

A bipyramidal crystal with the following dimensions, given as distances from a common origin to the faces, was used: distances to $(\overline{\mathbf{1}} 00)$ and $(100)=0.046 \mathrm{~mm}$; to $(\overline{11} 1)$ and $(11 \overline{1})=0.061 \mathrm{~mm}$; to $(\overline{1} 1 \overline{1})$ and $(\overline{1} 1)=0.062 \mathrm{~mm}$; to $(\overline{1} 11)$ and $(\overline{1} 1)=0.056 \mathrm{~mm}$; and to $(\overline{111})$ and $(111)=0.059 \mathrm{~mm}$. 
The crystal was mounted with the $a$ axis approximately along the $\phi$ axis of the diffractometer. Its orientation and cell dimensions were determined by measuring $\theta, \chi$, and $\phi$ for three non-coplanar reciprocal vectors, and the setting angles for all reflections could be calculated.

For determination of unit cell dimensions by least squares, $\theta$ angles of 8 reflections at high $\theta$ were measured.

Intensity data were collected using a scintillation counter and $\theta-2 \theta$ scan technique. The scan-speed was chosen to be 0.5 degrees per minute, with automatic choice of greater scan-speed for strong reflections. When an attenuation filter was needed to avoid counting losses, the proper one was automatically inserted into the primary beam.

Each reflection was scanned between $\theta_{1}=\theta-0.40^{\circ}$, and $\theta_{2}=\theta+0.40^{\circ}+0.15^{\circ} \operatorname{tg} \theta$, where $\theta$ is the Bragg angle for the $\alpha_{1}$ peak. The scan was performed by going from $\theta$ to $\theta_{1}$, then from $\theta_{1}$ to $\theta_{2}$, and finally from $\theta_{2}$ to $\theta$. The intensities over each scanning range were recorded at the end of each step. The background was measured for one half of the total scan time at $\theta_{1}$, and one half at $\theta_{2}$. This scan procedure provides a check of the setting angles.

Two reference reflections were measured at intervals of 50 reflections, and the setting angles of these two reflections were checked by horizontal and vertical half shutters.

The net intensities were brought to a common scale by using the intensity variations of the reference reflections. The lower limit for observed reflections was set equal to two times the standard deviation in net intensity. The standard deviation is $\left(I_{\mathrm{t}}+I_{\mathrm{b}}\right)^{\frac{1}{2}}$, where $I_{\mathrm{t}}$ is the total intensity, and $I_{\mathrm{b}}$ is the background intensity. Out of 1631 reflections with $\theta<70^{\circ}, 1373$ were found stronger than the lower limit. The remaining 258 reflections were assigned an intensity equal to the limit, and labelled as unobserved reflections.

Absorption $\left(\mu=193 \mathrm{~cm}^{-1}\right)$, Lorentz, and polarization corrections were carried out. A modified version of the absorption correction method described by Busing and Levy was applied, using a $6 \times 8 \times 10$ grid.

The calculated structure factors were based on the scattering curve of Stewart et al. ${ }^{5}$ for hydrogen, and the curves listed in International Tables ${ }^{6}$ for all other atoms. Using the $\Delta f^{\prime}$ and $\Delta f^{\prime \prime}$ values given by Cromer, ${ }^{7}$ the tellurium and sulphur scattering curves were corrected for anomalous dispersion by taking the amplitude of $f$ as the corrected value.

The structure was refined by a least squares, full-matrix program minimizing the function

$$
r=\sum W\left(\left|F_{\mathrm{o}}\right|-K\left|F_{\mathrm{c}}\right|\right)^{2}
$$

Table 1. Computer programs.

\begin{tabular}{|c|c|c|}
\hline Name & Function & Origin \\
\hline $\begin{array}{l}\text { CELL } \\
\text { BDLS } \\
\text { DIAN }\end{array}$ & $\begin{array}{l}\text { Cell dimensions } \\
\text { Least squares refinement } \\
\text { Distances and angles }\end{array}$ & $\begin{array}{l}\text { Weizmann Institute of } \\
\text { Science, Rehovoth, Israel }\end{array}$ \\
\hline $\mathrm{ABCD}$ & Absorption correction & $\begin{array}{l}\text { As above. Modified by the present } \\
\text { author, to take into account a general } \\
\text { orientation of the crystal }\end{array}$ \\
\hline $\begin{array}{l}\text { AEDI } \\
\text { PLAN }\end{array}$ & $\begin{array}{l}\text { Setting angles for the } \\
\text { diffractometer } \\
\text { Weighted least } \\
\text { squares planes }\end{array}$ & $\begin{array}{l}\text { Mr. Knut Maartman-Moe, Chemical } \\
\text { Institute, University of Bergen, } \\
\text { Norway }\end{array}$ \\
\hline $\begin{array}{l}\text { DATI } \\
\text { ASEN } \\
\text { ZACH }\end{array}$ & $\begin{array}{l}\text { Data processing } \\
\text { Fourier summation } \\
\text { Extinction correction }\end{array}$ & Present author \\
\hline
\end{tabular}

Acta Chem. Scand. 25 (1971) No. 3 
where $K$ is a scale factor, and the weight, $W$, is the inverse of the variance of $F_{\mathrm{o}}$. The variance of $F_{0}$ is

$$
\sigma^{2}\left(F_{\mathrm{o}}\right)=F_{\mathrm{o}}^{2}\left[I_{\mathrm{t}}+I_{\mathrm{b}}+k^{2}\left(I_{\mathrm{t}}-I_{\mathrm{b}}\right)^{2}\right] / 4\left(I_{\mathrm{t}}-I_{\mathrm{b}}\right)^{2}
$$

where $k$ may be interpreted as the relative standard deviation in the scaling curve based on reference reflections. It was given the value 0.008 . Non-observed reflections for which $K\left|F_{\mathrm{c}}\right|$ is greater than the observable limit, are included in the refinement with $\left|F_{\mathrm{o}}\right|$ equal to the observable limit.

The calculations were carried out on an IBM 360/50 H computer. The programs used are listed in Table 1.

\section{CRYSTAL DATA}

The crystals of tellurium dibenzenethiosulphonate are orthorhombic. Based on 8 high-angle $\theta$-values measured on the diffractometer, a least squares procedure gave the following cell dimensions, with standard deviations in parentheses:

$$
a=14.467(1) \AA ; b=11.137(1) \AA ; c=10.455(1) \AA ; V=1684.5(3) \AA^{3} .
$$

Other pertinent values from the earlier study of Øyum and Foss ${ }^{2}$ are

$$
M=474.07 ; F(000)=1020 ; Z=4 \text {. }
$$

Systematic absences are $h k 0$ when $h+k$ is odd, $h 0 l$ when $l$ is odd, $0 k l$ when $k$ is odd. The uniquely determined space group is Pbcn (No. 60).

\section{REFINEMENT OF THE STRUCTURE .}

With four molecules in the unit cell, a two-fold rotation axis must pass through the tellurium atom. Using the positional and thermal parameters given by Øyum and Foss ${ }^{2}$ for the non-hydrogen atoms, refinement by least squares was started. Refinement on the scale factor, positional parameters and individual thermal parameters resulted in an $R$ value of 0.065 . Introduction of anisotropic thermal parameters for the tellurium and sulphur atoms lowered the $R$ value to 0.051 , and introduction of anisotropic thermal parameters for the rest of the atoms lowered it to 0.040. Applying the test of $\mathrm{Ha}$ milton, ${ }^{8}$ both changes in the model were found to be significant at the $0.5 \%$ level.

There seemed to be a marked tendency of $\left|F_{0}\right|$ values for strong, loworder reflections to be smaller than the corresponding $K\left|F_{\mathrm{c}}\right|$ values. A correction for extinction was therefore carried out, using the expression given by Zachariasen. ${ }^{9}$ The absorption term in this expression was set equal to 1 . With $I_{\text {o }}$ on an absolute scale, the value of the extinction parameter, $C$, was found to be $4.7 \times 10^{-7}$. Additional refinement on the parameters mentioned above lowered the $R$ value to 0.038 .

A three-dimensional difference Fourier summation at this point showed peaks between 0.40 and $0.67 \mathrm{e} / \AA^{3}$ at the positions where the hydrogen atoms would be expected. The hydrogen positions were taken from the difference map, and a refinement with hydrogen included was attempted. This attempt was not successful, however, as the hydrogen atoms were shifted to 
unreasonable positions, with $\mathrm{C}-\mathrm{H}$ bond lengths between 0.81 and $1.12 \AA$, and one of the $\mathrm{C}-\mathrm{C}-\mathrm{H}$ bond angles as low as $99^{\circ}$. The hydrogen atoms were therefore left out of the structure factor calculations and the refinement.

In a final full-matrix, least squares cycle no shift was greater than 0.4 times the standard deviation. The final $R$ value, with non-observed reflections included when $K\left|F_{\mathrm{c}}\right|$ exceeds the observable limit, is 0.038 . The final atomic coordinates are listed in Table 2, and the thermal parameters in Table 3. The structure factors based on the final parameters are listed in Table 4.

Table 2. Atomic coordinates in fractions of cell edges. Standard deviations from the least squares refinement in parentheses.

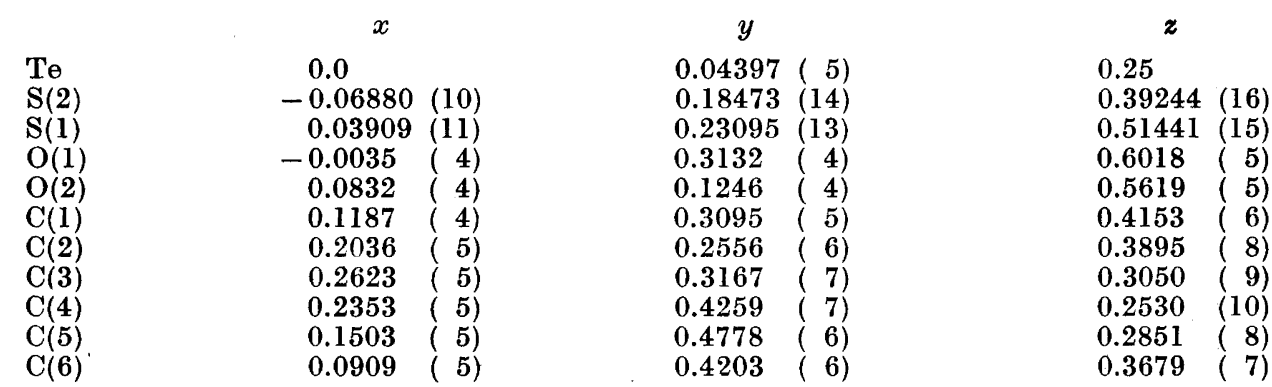

Table 3. Anisotropic thermal parameters $\left(\AA^{2}\right)$ in the form $\exp \left[-2 \pi^{2}\left(h^{2} a^{-2} U_{11}+\cdots+\right.\right.$ $\left.\left.2 h k a^{-1} b^{-1} U_{12}+\cdots\right)\right]$. All values have been multiplied by $10^{4}$. Standard deviations in parentheses.

\begin{tabular}{lrrrrrr} 
& \multicolumn{1}{c}{$U_{11}$} & $U_{22}$ & $U_{33}$ & $U_{12}$ & \multicolumn{1}{c}{$U_{23}$} & \multicolumn{1}{c}{$U_{13}$} \\
$\mathrm{Te}$ & $426(3)$ & $396(3)$ & $402(3)$ & 0 & 0 & $4(3)$ \\
$\mathrm{S}(2)$ & $391(7)$ & $453(8)$ & $442(9)$ & $38(6)$ & $-14(7)$ & $68(7)$ \\
$\mathrm{S}(1)$ & $615(8)$ & $428(7)$ & $343(8)$ & $-25(7)$ & $10(7)$ & $10(7)$ \\
$\mathrm{O}(1)$ & $1063(35)$ & $625(26)$ & $469(27)$ & $-39(33)$ & $-151(22)$ & $189(33)$ \\
$\mathrm{O}(2)$ & $751(29)$ & $551(25)$ & $574(30)$ & $-19(23)$ & $182(24)$ & $-129(25)$ \\
$\mathrm{C}(1)$ & $493(31)$ & $412(28)$ & $436(33)$ & $-65(25)$ & $-20(27)$ & $-32(27)$ \\
$\mathrm{C}(2)$ & $514(34)$ & $554(37)$ & $670(47)$ & $38(30)$ & $-31(37)$ & $-56(34)$ \\
$\mathrm{C}(3)$ & $490(37)$ & $700(49)$ & $909(58)$ & $-57(34)$ & $82(42)$ & $34(37)$ \\
$\mathrm{C}(4)$ & $596(37)$ & $746(46)$ & $900(54)$ & $-199(32)$ & $-21(59)$ & $49(50)$ \\
$\mathrm{C}(5)$ & $641(38)$ & $509(41)$ & $789(64)$ & $-115(30)$ & $28(34)$ & $66(36)$ \\
$\mathrm{C}(6)$ & $669(38)$ & $387(29)$ & $589(44)$ & $-39(27)$ & $30(31)$ & $-9(33)$
\end{tabular}

\section{RESULTS}

The tellurium dibenzenethiosulphonate molecule has been described by Øyum and Foss. ${ }^{2}$ Here the new results will be recorded, and the differences, although not great, between the present investigation and the older one, will be pointed out.

Bond lengths and angles, as calculated from the coordinates of Table 2, are listed in Table 5. Coordinate covariances and standard deviations in unit cell dimensions have been neglected. A drawing of the molecule, with the most important bond lengths and angles, is presented in Fig. 1.

Acta Chem. Scand. 25 (1971) No. 3 
Table 4. Observed and calculated structure factors ( $\times 10)$. Unobserved reflections are indicated by a minus sign on $F(O)$ and included at the threshold values.

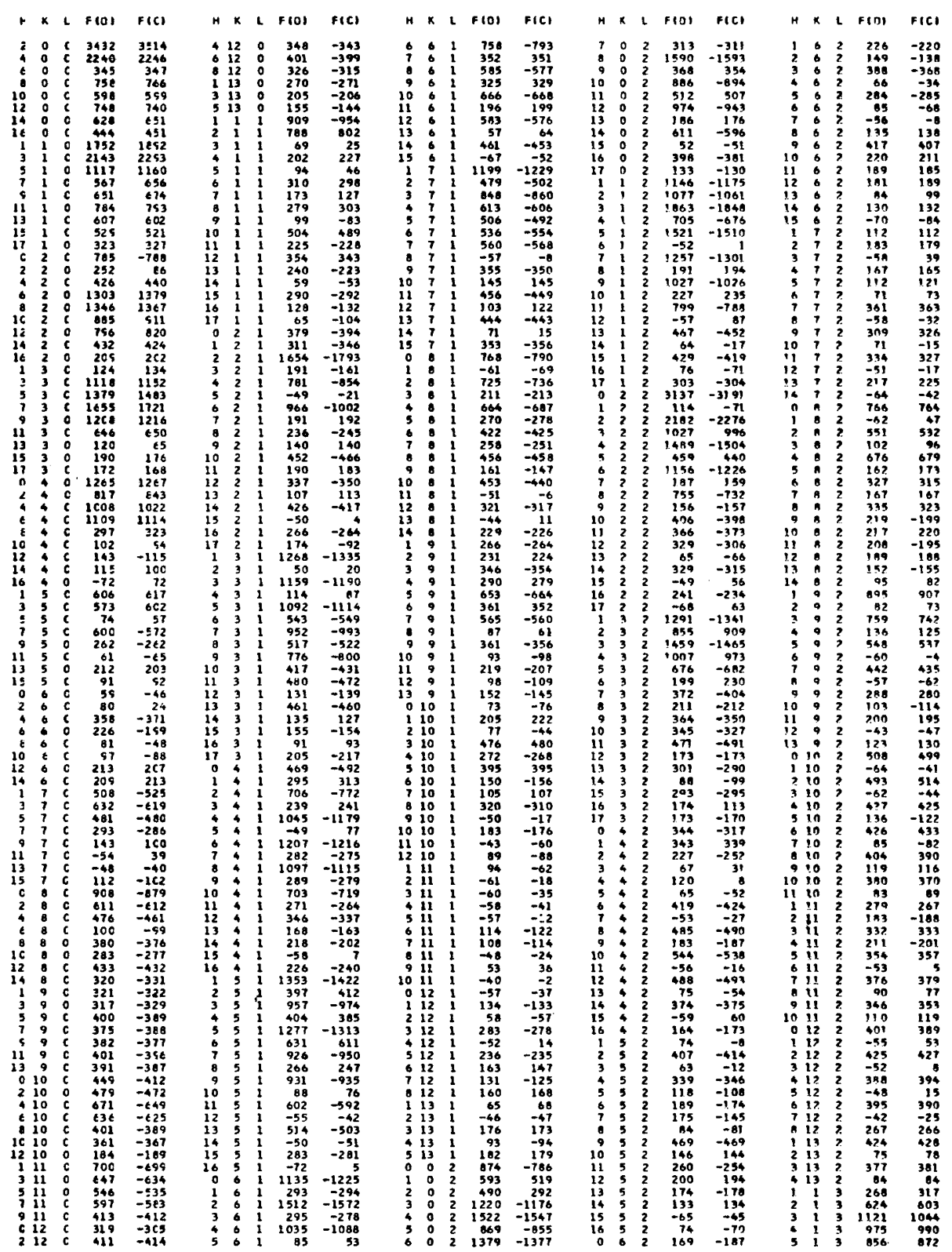

Acta Chem. Scand. 25 (1971) No. 3 
TELLURIUM DIBENZENETHIOSULPHONATE

Table 4. Continued.

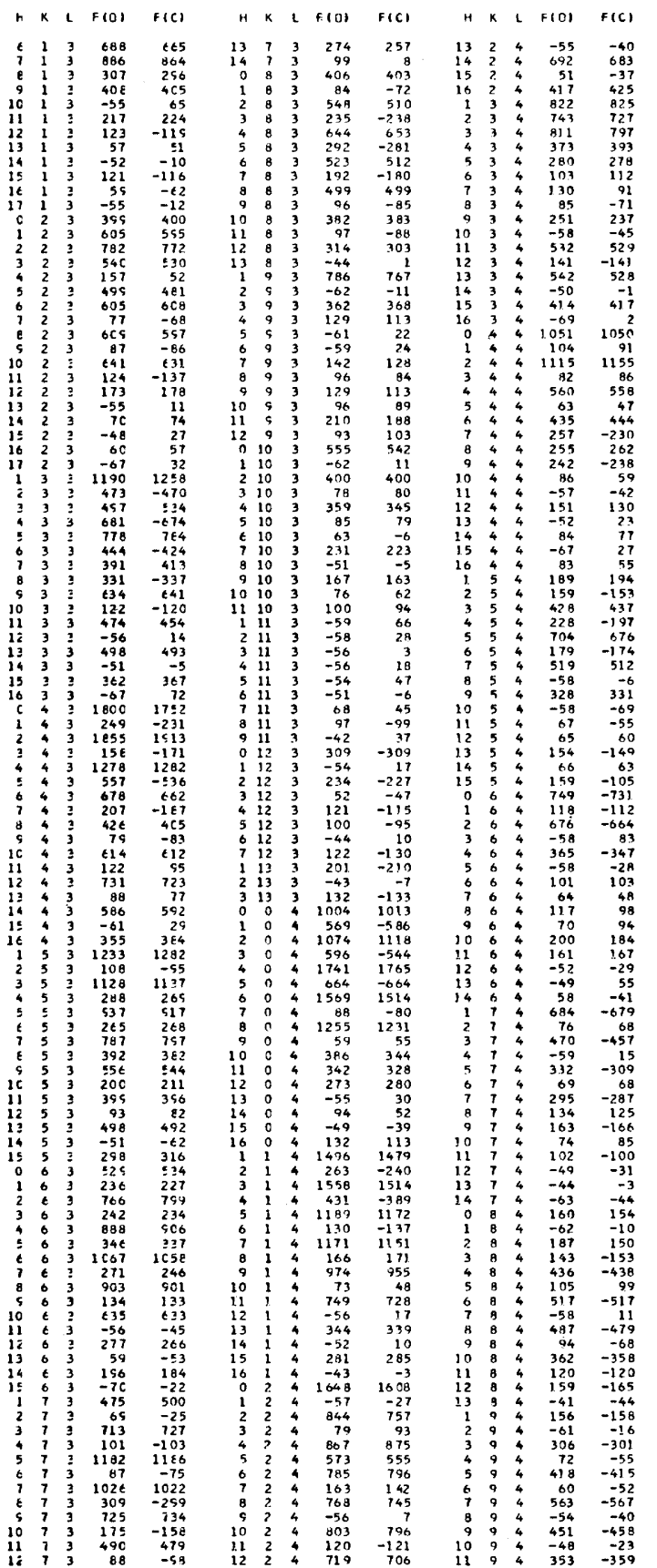

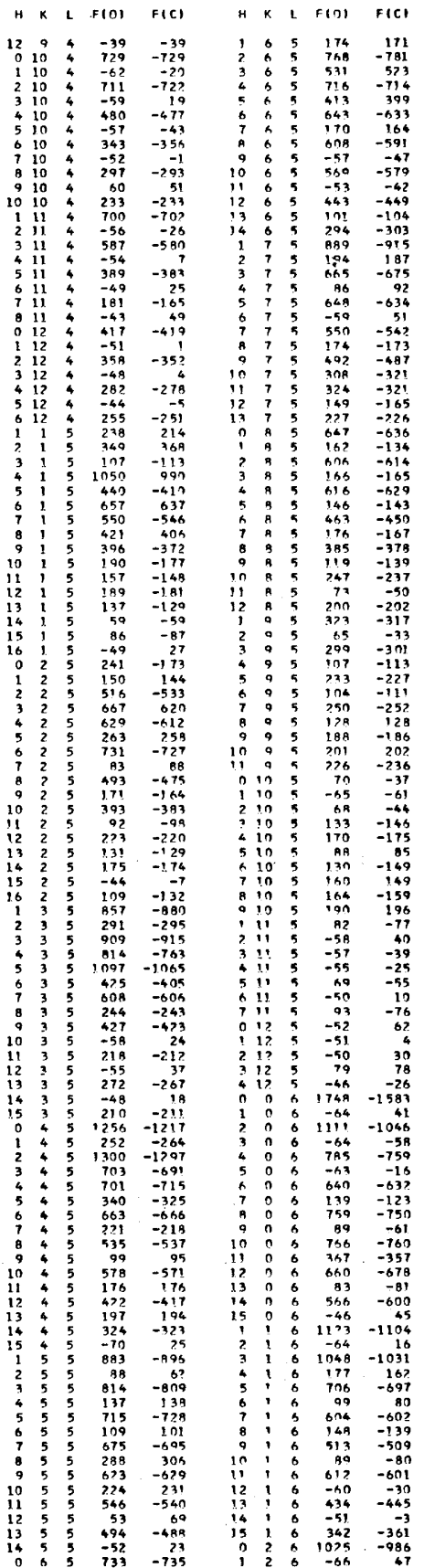

Acta Chem. Scand. 25 (1971) No. 3 
Table 4. Continued.

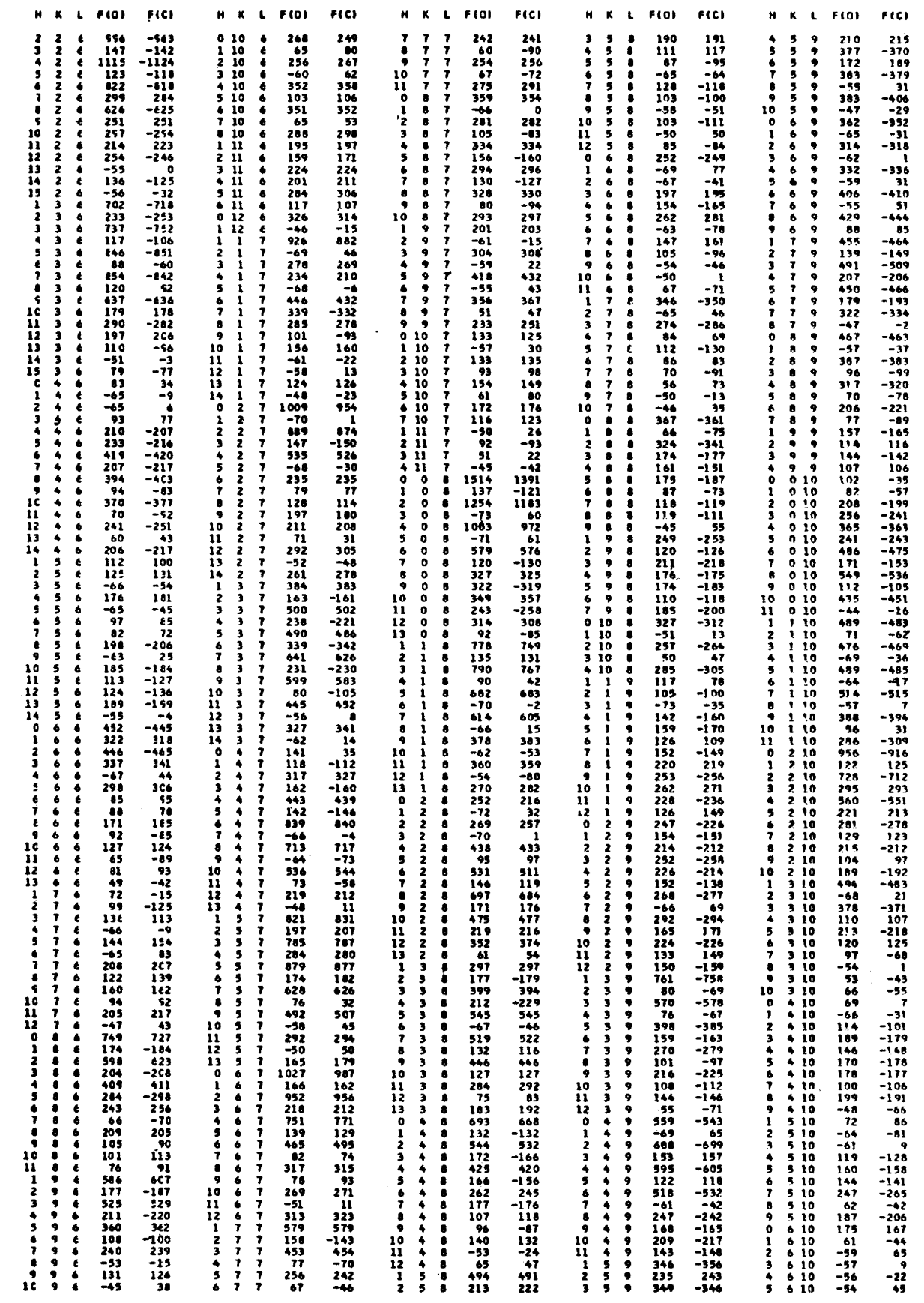

Acta Chem. Scand. 25 (1971) No. 3 
Table 4. Continued.
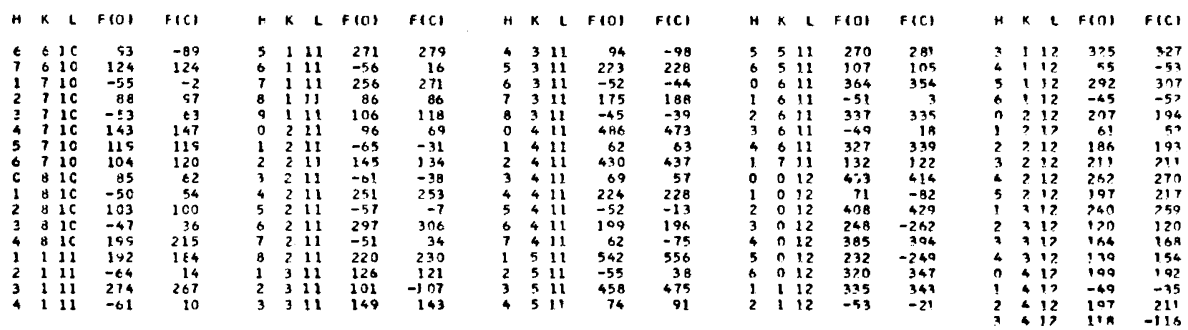

Table 5. Bond lengths $(\AA)$ and angles $\left({ }^{\circ}\right)$. Standard deviations in parentheses. A prime denotes an atom generated by the twofold axis of symmetry.

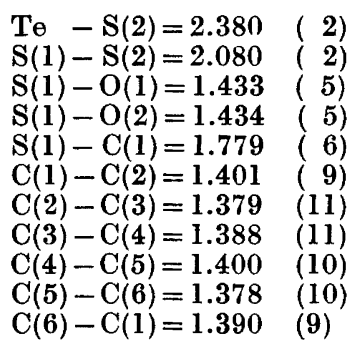

Fig. 1. The tellurium dibenzenethiosulphonate molecule as seen along the twofold rotation axis.

$$
\begin{array}{ll}
\angle \mathrm{S}(9)-\mathrm{Te}-\mathrm{S}\left(2^{\prime}\right)=97.61 & (6) \\
\angle \mathrm{Te}-\mathrm{S}(2)-\mathrm{S}(1)=103.46 & (7) \\
\angle \mathrm{S}(2)-\mathrm{S}(1)-\mathrm{O}(1)=103.1 & (3) \\
\angle \mathrm{S}(2)-\mathrm{S}(1)-\mathrm{O}(2)=110.0 & (3) \\
\angle \mathrm{S}(2)-\mathrm{S}(1)-\mathrm{C}(1)=104.5 & (3) \\
\angle \mathrm{O}(1)-\mathrm{S}(1)-\mathrm{O}(2)=119.9 & (3) \\
\angle \mathrm{O}(1)-\mathrm{S}(1)-\mathrm{C}(1)=109.6 & (3) \\
\angle \mathrm{O}(2)-\mathrm{S}(1)-\mathrm{C}(1)=108.6 & (3) \\
\angle \mathrm{S}(1)-\mathrm{C}(1)-\mathrm{C}(2)=119.0 & (5) \\
\angle \mathrm{S}(1)-\mathrm{C}(1)-\mathrm{C}(6)=117.2 & (5) \\
\angle \mathrm{C}(1)-\mathrm{C}(2)-\mathrm{C}(3)=117.6 & (6) \\
\angle \mathrm{C}(2)-\mathrm{C}(3)-\mathrm{C}(4)=120.0 & (7) \\
\angle \mathrm{C}(3)-\mathrm{C}(4)-\mathrm{C}(5)=121.0 & (8) \\
\angle \mathrm{C}(4)-\mathrm{C}(5)-\mathrm{C}(6)=120.5 & (7) \\
\angle \mathrm{C}(5)-\mathrm{C}(6)-\mathrm{C}(1)=117.1 & (6) \\
\angle \mathrm{C}(6)-\mathrm{C}(1)-\mathrm{C}(2)=123.8 & (6)
\end{array}
$$

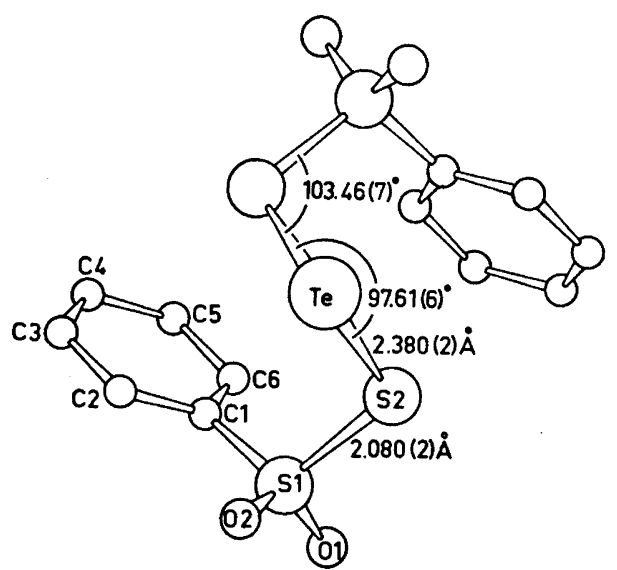

Acta Chem. Scand. 25 (1971) No. 3 
Since the molecule possesses a two-fold axis of symmetry, the non-planar $\mathrm{S}-\mathrm{S}-\mathrm{Te}-\mathrm{S}-\mathrm{S}$ chain occurs in the trans form, with the terminal sulphur atoms on opposite sides of the plane through the three middle atoms.

The greatest difference between the two investigations is in the $\mathrm{Te}-\mathrm{S}(2)$ bond length, which is now found to be $2.380(2) \AA$. The older value is $2.41 \AA$, with a probable error of $0.03-0.04 \AA$. It is interesting to note that a Fourier map from the earlier study indicates a bond length of $2.39 \AA$.

The dihedral angle between the $\mathrm{S}(1)-\mathrm{S}(2)-\mathrm{Te}$ and the $\mathrm{S}(2)-\mathrm{Te}-\mathrm{S}\left(2^{\prime}\right)$ planes is $97.4^{\circ}$. The $S(1)-S(2)$ bond length, $2.080(2) \AA$, is in excellent agreement with the earlier value. In the complex, trans-dibenzenethiosulphonato-bis(trimethylenethiourea)tellurium(II), ${ }^{1}$ the $\mathrm{S}-\mathrm{S}$ bond length is $2.018(4) \AA$. This difference in the $\mathrm{S}-\mathrm{S}$ bond lengths is thought to be caused by the difference in the nature of the $\mathrm{Te}-\mathrm{S}$ bond in the complex relative to the uncomplexed compound, which is the subject of the present study.

The coordination around the $S(1)$ atom is approximately tetrahedral, with the greatest deviation for the $\mathrm{O}(1)-\mathrm{S}(1)-\mathrm{O}(2)$ angle, which is $119.9(3)^{\circ}$. The bond lengths and angles involved in this coordination are in good agreement with the values given by $\varnothing y$ ym and Foss. ${ }^{2}$

The atoms of a least squares plane through the benzene ring do not deviate more than $0.013 \AA$ from the plane. $\mathrm{S}(1)$ is $0.095 \AA$ from this plane, on the same side as Te, while $\mathrm{O}(1)$ and $\mathrm{O}(2)$ are 0.779 and $0.012 \AA$ from it, on the opposite side.

Excluding the $S(1)-S(2)$ bond length, the dimensions of the benzenethiosulphonate group are very similar to the dimensions found for the same group in the complex referred to above. In both compounds one of the oxygen atoms is near the plane of the benzene ring, and the $\mathrm{C}(6)-\mathrm{C}(1)-\mathrm{C}(2)$ angle is somewhat large.

Acknowledgement. I wish to thank Prof. Olav Foss for his interest. This investigation is in part financially supported by Norges Almenvitenskapelige Forskningsråd (Norwegian Research Council for Science and Humanities I.

\section{REFERENCES}

1. Ase, K. Acta Chem. Scand. 23 (1969) 3206.

2. Øyum, P. and Foss, O. Acta Chem. Scand. 10 (1956) 279.

3. Foss, O. Acta Chem. Scand. 6 (1952) 521.

4. Busing, W. R. and Levy, A. H. Acta Cryst. 10 (1957) 180.

5. Stewart, F., Davidson, E. R. and Simpson, W. T. J. Chem. Phys. 42 (1965) 3175.

6. International Tables for X-Ray Crystallography, Kynoch Press, Birmingham 1962, Vol. III, p. 202.

7. Cromer, D. T. Acta Cryst. 18 (1965) 17.

8. Hamilton, W. C. Acta Cryst. 18 (1965) 502.

9. Zachariasen, W. H. Acta Cryst. 16 (1963) 1139.

Received July 13, 1970. 